\title{
Üç-Boyutlu Çok-Kullanıcılı Sanal Ortamlarda Buradalığın İncelenmesi
}

\section{An Investigation of Presence in Three-Dimensional Multi-User Virtual Environments}

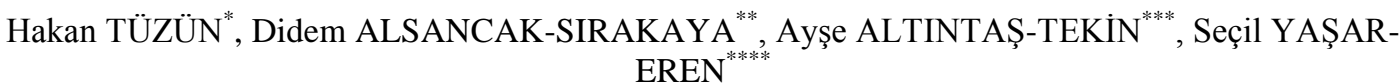

ÖZ: Bu çalışmanın amacı öğrenme için yeni olanaklar sunan üç-boyutlu çok-kullanıcılı sanal ortamları kullanan katılımcıların bu ortamlara yönelik buradalık düzeylerinin incelenmesidir. Çalışmada ayrıca katılımcıların buradalık düzeylerinde cinsiyetlerine göre bir farklılık olup olmadığı da incelenmiştir. Ek olarak ortam üzerinden yapılan görüşmelerde araştırmacılar tarafindan tutulan alan notları ve katılımcılar ile yapılan görüşmeler sonucu elde edilen nitel veriler ile katılımcıların buradalık algıları nitel açıdan incelenmiştir. Çalışmanın katılımcılarını 2010-2011 yılı Bahar döneminde İç Anadolu Bölgesindeki büyük bir devlet üniversitesinde, Eğitim Fakültesi BÖTE bölümünde Programlama Dilleri II dersine devam etmekte olan 24 öğrenci oluşturmaktadır. Çalışma kapsamında veri toplama aracı olarak Sosyal Buradalık Ölçeği ve Sanal Ortamda Buradalık Ölçeği kullanılmıştır. Nitel verilerin elde edilmesi için alan notları ve görüşmelerden yararlanılmıştır. Çalışmanın bulgularına göre katılımcıların buradalık düzeylerinin orta düzeyin üzerinde olduğu, buradalık düzeyinin cinsiyete göre farklılaşmadığı bulunmuştur. Ayrıca katılımcıların görüşleri doğrultusunda buradalığın oluşmasını sağlayan ortam özellikleri belirlenmiştir.

Anahtar sözcükler: üç-boyutlu çok-kullanıcılı sanal ortamlar, buradalık, sosyal buradalık

\begin{abstract}
The aim of the present study was to analyze the presence levels of participants who use threedimensional multi-user virtual environments, which present new opportunities for learning. In addition, the participants' presence levels were compared in terms of gender. Participants' presence levels were examined qualitatively through online interviews, field notes, and interviews with the participants. The sample comprised 24 students, who attended Programming Languages II course in a Computer Education and Instructional Technology Department at a large state university in Central Anatolia Region of Turkey in 2011 Spring semester. Social Presence Scale and Virtual Environment Presence Questionnaire were used as data collection instruments. Field notes and interviews were used in order to obtain qualitative data. The results revealed that participants had a medium presence level and these levels did not differ in terms of gender. Also, the environmental factors leading to the formation of presence were identified in line with participants' opinions.
\end{abstract}

Keywords: three-dimensional multi-user virtual environments, presence, social presence

\section{GİRIŞ}

İnsanların yaşamını kolaylaştırmak amacıyla kullanılan teknolojideki değişim ve gelişimler Bilgi ve İletişim Teknolojilerini (BİT) önemli ölçüde etkilemiştir. Yaşanan değişimlerle birlikte bilginin üretilme, yayılma, depolanma ve paylaşılma sürecinde etkin olarak yer alan BİT yaşamın her alanında değişikliklere neden olmuştur (Tor ve Erden, 2004). Bu değişikliklerden etkilenen alanlardan bir tanesi de hiç kuşkusuz eğitim sistemidir. BİT, eğitimin yürütülme sürecindeki değişiklikleri beraberinde getirmiştir. Teknolojideki bu değişim ve gelişimlerin gerek eğitimi gerekse bireyleri etkilemesiyle birlikte işbirlikli, etkin katılımı gerektiren, bireyler arasında etkileşim unsurunu ön plana çıkaran, sürekli gelişim gösteren, her

* Doç. Dr., Hacettepe Üniversitesi, Eğitim Fakültesi, BÖTE Bölümü, Ankara/Türkiye, e-posta: htuzun@ @acettepe.edu.tr **Aş̧. Gör. Dr., Ahi Evran Üniversitesi, Eğitim Fakültesi, BÖTE Bölümü, Ankara/Türkiye, e-posta: alsancakdidem@gmail.com

*** Öğretmen, Milli Eğitim Bakanlığı, e-posta: aysealtintas86@gmail.com

**** Öğretmen, Milli Ĕgitim Bakanlığı, e-posta: secilysr@gmail.com 
geçen gün var olanları arasına bir yenisi eklenen teknolojiler bize eğitim-öğretim sürecinde yeni olanaklar sunmaktadır.

$\mathrm{Bu}$ teknolojilerden biri hem geleneksel eğitimde hem de uzaktan eğitimde kullanılabilen üç-boyutlu sanal ortamlardır. Üç-boyutlu sanal ortamlar klasik BİT uygulamalarından farklı olarak her zaman her yerde kullanılabilme özelliğinden dolayı daha erişilebilir bir hale gelmiş (Dickey, 2005), eğitimde güçlü ve geleceği olan bir araç olarak görülmeye başlanmıştır (Mikropoulos ve Natsis, 2011). Başlangıçta uzaktan etkileşim amacıyla geliştirilen bu ortamlar daha sonra eğitim amacıyla kullanılmaya başlanmıştır. Eğitim ortamlarının hazırlanmasında Active Worlds (AW) ve Second Life en çok kullanılan üç-boyutlu sanal ortam örneklerindendir. Üç-boyutlu sanal ortamlar deneyimsel öğrenme ile uyumlu olması nedeniyle özellikle eğitim amaçlı kullanım için uygundur (Perera, Allison, Nicoll ve Sturgeon, 2009). Bu ortamlar özellikle birbirinden uzakta olan öğrenenlerin kendi gereksinimleri doğrultusunda ortamı şekillendirebildiği ve bilgiyi paylaşabildiği dinamik ve esnek ortamlardır (Prasolova-Forland, 2008).

Dickey (2005), üç-boyutlu sanal dünyaları kişilerin üç-boyutlu sanal bir çevrede dolaştığ1 ve gerek diğerleri ile gerekse çevre ile etkileşimde bulunduğu, İnternet üzerinden kullanılan masaüstü sanal gerçeklik altyapısı olarak tanımlamıştır. Başka bir çalışmada üç-boyutlu sanal dünyalar, bireylerin avatarlar aracılığıyla eşzamanlı bir şekilde etkileşimde bulunduğu bilgisayar destekli ortamlar olarak tanımlanmıştır (González, Santos, Vargas, Martín-Gutiérrez ve Orihuela, 2013). Etkileşimli üç-boyutlu ortam, kullanıcıların avatarlara bürünmesi ve etkileşimli iletişim araçları bu tür ortamların karakteristik özelliklerindendir (Dickey, 2005). Dalgarno ve Lee (2010), üç-boyutlu ortamların faydalarını bağlamsal simülasyonları desteklemesi, motivasyonu arttırması, tecrübeye dayalı olması, durum-merkezli öğrenmeyi kolaylaştırması ve işbirliğine dayalı öğrenmeyi sağlaması şeklinde ifade etmiştir. Üç-boyutlu sanal dünyalar ayrıca avatarlar üzerinden kullanıcı etkileşimi; yüz ifadesi, jest, mimik ve çoklu iletişim yöntemleri ile ortamda buradalık ve geniş bir kullanıcı topluluğuna ulaşma gibi özellikler sağlar (Baydaş, Karakus, Topu, Yilmaz, Ozturk ve Goktas, 2015). Üç-boyutlu çok-kullanıcılı sanal ortamlar öğrenenlerin avatar olarak ifade edilen karakterler tarafından temsili ile diğer öğrenenlerle etkileşim içinde olmalarını sağlar (Erlandson, Nelson ve Savenye, 2010). Her bir kullanıcı avatar adı verilen karakterler tarafindan görsel olarak temsil edilir. Avatarlar, otantik kullanıcıların sanal dünyadaki temsilleridir. Kullanıcılar üç-boyutlu ortamlarda kendi istedikleri şekilde avatarlarını seçebilir, görünümlerini özelleştirebilir, hareket ettirebilir ve diğer kullanıcıların avatarları ile iletişime geçirebilir. Ayrıca farklı kamera açılarına göre (birinci kişi, üçüncü kişi gibi) avatarı görüntüleyebilirler. Avatarlar kullanıcılara kendilerini diğerlerine ifade etme olanağı da sağlamaktadır. Sonuçta üç-boyutlu dünyalarda kullanıcılar yalnızca bir ekranda bir karakteri manipüle etmemekte, artık sosyo-kültürel bir çevre içinde yer almakta ve çevre sakinleri ile etkileşime geçmektedir. Katılımcıların kişilikleri gibi faktörler sanal ortamlardaki davranışları etkilemektedir (McCreery, Schrader, Krach ve Boone, 2013). Tüm bu özellikleri içinde barındıran çok-kullanıcılı sanal ortamlardan birisi de Active Worlds ortamıdır.

Active Worlds, Second Life gibi sanal dünyalara verilebilecek örneklerden biridir (Bulu ve İşler, 2011; Tüzün, 2010). AW, İnternet bağlantısı olan herkese açık olan bir sanal gerçeklik ortamıdır. Bu sanal ortam geniş bir sanal evrenden (virtual universe) oluşmakta ve bu sanal evren de alt sanal dünyaları (virtual worlds) içermektedir. Kişiler bu sanal evrende bir vatandaş hesabı (citizen) açarak diğerlerinin ortaya koydukları sanal dünyalar içerisinde gezebilecekleri gibi bu sanal evren içerisinde kendi sanal dünyalarını da açabilirler. Bu sanal dünyalar gezintilerin düzenlenmesi, alışveriş, bilimsel verilerin incelenmesi, diğer insanlarla işbirliği yapılması, arkadaşlık etmek ve ticaret gibi değişik amaçlar için kullanılabilir. Bu amaçlar dışında Active Worlds, eğitimcilerin taleplerine paralel olarak Active Worlds Eğitsel Evrenini eğitim kurumlarının, öğretmenlerin ve öğrencilerin kullanımına sunmuştur. Bu sanal dünyalar topluluğu aracılığıyla eğitimciler var olan öğrenme kuramlarını araştırabilmekte, yaratıcı müfredat 
tasarımları yapabilmekte ve sosyal öğrenme ortamlarını oluşturup inceleyebilmektedir. Ek olarak, Active Worlds yazılımı 4.1 sürümünden itibaren VoIP protokolü (Voice over Internet Protocol) üzerinden kullanıcıları arasında sesli olarak iletişim kurulmasına olanak sağlamaktadır. $\mathrm{Bu}$ tasarım sağlarlığı kullanıcıların yazarak (chat) iletişim kurma yanında daha sezgisel bir yöntem olan doğrudan konuşma ile iletişim kurmalarına olanak sağlamaktadır.

Second Life gibi üç-boyutlu çok-kullanıcılı sanal bir ortamda öğrenenlerin birbirleriyle iletişim kurması ve ortamla olan gerçek-zamanlı etkileşimleri sanal ortamda buradalık algısının oluşmasını sağlayabilir (Edirisingha, Nie, Pluciennik ve Young, 2009). Bu tür sanal ortamlarda sosyal buradalık gözetilmesi gereken bir özelliktir (Özdinç, 2010). Steuer (1992), buradalık hissinin sanal dünyalardaki deneyimler için önemli olduğunu ve bu ortamların tasarımında bu konuya dikkat edilmesi gerektiğini vurgulamıştır. Benzer şekilde Dickey (2005) çok-kullanıcılı sanal ortamların işbirlikli öğrenme deneyimi, orada olma algısı, buradalık algısı ve topluluk algısı sağladığını ifade etmiştir.

Buradalığın çeşitli tanımları vardır. Gunawardena (1995), buradalık kavramını bir kişinin iletişim ortamında gerçek bir kişi olarak algılanma derecesi olarak ifade ederken; Lee (2004) sanal nesnelerin duyusal ya da duyusal olmayan yollarla gerçek nesneler olarak algılandığ psikolojik durum olarak tanımlamıştır. Steuer'a (1992) göre ise fiziksel otantik bir ortamın aksine aracılı bir ortamda bulunma hissi derecesidir. Kısacası buradalık, aracı bir ortam içinde bulunma duygusudur (Williams, 2014).

Sosyal buradalık, çevrim-içi öğrenme ortamlarında sosyal etkileşimin niteliğini incelemede kullanılan bir kavramdır (Kim, Kwon ve Cho, 2011). Alanyazında çeşitli sosyal buradalık tanımları bulunmaktadır. Kreijns (2004) tarafından katılımcıların diğer katılımcıları gerçek bireyler olarak algılayabilmeleri olarak tanımlanmaktadır. Short, Williams ve Christie (1976) tarafından ise etkileşim esnasında diğer bireylerin dikkatini çekebilme gücü ve kişilerarası ilişkilerdeki dikkat çekiciliğin sonucu olarak tanımlanmıştır. Sosyal buradalık bir öğrenenin öğretmen ve diğer öğrenenler ile olan fiziksel uzaklık algısını etkileyen sosyal ve iletişimsel bir faktördür. Diğer öğrenenlerle bağlanmışlık ve hazır bulunma algılarının psikolojik derecesidir (So ve Brush, 2008). Whiteman'a (2002) göre iletişim sürecine dahil olma hissi, Tu'ya (2000a) göre bireyler arasındaki farkındalık derecesi, Gunawardena ve Zittle'a (1997) göre ise iletişimde bir kişinin kendisini gerçek insan olarak algılama derecesidir. Sosyal buradalık çevrim-içi sosyal etkileşimi teşvik etmek ve geliştirmek için gereklidir (Tu, 2000b).

Çevrim-içi ortamlarda muhatap olunan kişiden alınan mesajlarda sosyal ipuçlarının yokluğundan dolayı bu kişinin duygularının farkına varma ve anlama zorlaşabilir. Örneğin metin-tabanlı konuşmalarda ve sesli konferanslarda kafa sallama ve göz gezdirme gibi sosyal ipuçları kullanılamaz, karşıdakinin yaptıklarının farkına varılamaz. Ancak çevrim-içi sosyal etkileşimde kullanılan sözel olmayan araçların kullanımında kişiden kişiye duyguları geçirmede yine sosyal buradalık önemli bir role sahiptir. (Derks, Fischer ve Bos, 2008). Üç-boyutlu ortamlarda kullanılan tasarım sağlarlıkları gerçeklik hissini sanal dünya ortamlarına taşıyarak bireyin sanal ortamda olma hissini sağlayabilir (Bulu, 2012). Yüz ifadesi, bakış açısı, duruş, elbise ve sözel olmayan iletişim unsurlarıyla ilgili ortam özellikleri iletişim ortamında sosyal bulunuşluk algısına katkı sağlar (Gunawardena ve Zittle, 1997). Yüz-yüze ya da çevrim-içi her türlü eğitim ortamında sosyal buradalık oluşturmanın amacı öğretmen ve diğer katılımcıların kolaylıkla hissedilebileceği bir konfor düzeyini oluşturmaktır (Arogan, 2003). Ortamda sosyal buradalık eksik olduğu zaman katılımcılar ortamı resmi bir ortam olarak görmektedir.

Öğrencilerin sosyal buradalıklarının arttırıldı ğı çevrim-içi sınıf ortamları bazı öğrencilerde öğrenme niteliğinin artmasına yardımcı olabilir (Newberry, 2001). Sosyal buradalık öğrenmede dahil etme (kimlik belirlemek için gerekli), kontrol (uygulama liderliği ve birinin becerisini geliştirmek için gerekli) ve etkilemeyi (insanlarla iletişim kurmak için gerekli) yönlendirir (Whiteman, 2002). Sosyal buradalık uzaktan eğitim ortamlarında kişiler arası ilişkileri anlamada 
anahtar bir kavramdır. Sosyal buradalık arttığı zaman katılımcılar arasındaki kişiler arası iletişim de artar. Tersine, sosyal buradalık düşük olduğu zaman mesajlar daha resmi olur, çünkü sözel ve sözel olmayan göstergeler az olduğu zaman katılımcılar diğer katılımcıların buradalıklarına daha az dikkat ederler (Walter ve Burgoon, 1992). Sallnas (2005) tarafından yapılan çalışmada işbirlikli sanal ortamlarda sesli sohbet ve metin-tabanlı sohbet karşılaştırmaları yapılmış ve katılımcıların ifade ettikleri buradalık ve sosyal buradalığın sesli durumda metine göre anlamlı derecede yüksek olduğu belirlenmiştir. Ayrıca katılımcılar görevi gerçekleştirmek için metintabanlı sohbette sese göre daha fazla zaman harcamışlardır. Ayrıca Hammick ve Lee (2014) sanal gerçekliğin iki ana boyutu olan etkileşim ve buradalığ 1 hissetme algısını ölçmüş ve buradalık hissinin iletişim endişesinin önemli bir belirleyicisi olduğunu bulmuştur. Bu bağlamda sanal dünyalarda buradalığı incelemenin önemine dikkat çekilmektedir.

Diğer taraftan alanyazında yapılan çalışmalar incelendiğinde birçok çalışmada cinsiyet faktörüne yer verildiği ve sanal ortamlar üzerine yapılan çalışmaların da cinsiyet farklılıklarını ele aldığ görülmektedir. Parsons ve arkadaşları (2004) sanal ortamlarda zihinsel ve mekansal yön belirlemede cinsiyet farklılıklarını incelemiş ve sanal ortamda cinsiyetin etkisi olmadığı sonucuna ulaşmıştır. Üç-boyutlu çok-kullanıcılı sanal ortamların kullanımına yönelik yapılan başka bir çalışmada ise önemli cinsiyet farklılıkları bulunmuștur (Siriaraya ve Ang, 2012). Felnhofer, Kothgassner, Hauk, Beutl, Hlavacs ve Exner (2014) işbirlikli sanal ortamlarda fiziksel ve sosyal buradalığı cinsiyet açısından incelemiş; fiziksel buradalıkta cinsiyet farkl11ıkları bulunurken sosyal buradalıkta cinsiyet farkl11ıkları bulunmamıştır. Sanal ortamlarda iletişimde mekansal işaretlerin ve cinsiyetin sözel davranışlara etkisinin incelendiği bir çalışmada ise yine cinsiyet faktörünün etkili olduğu bulunmuştur (Wua, Mattingly ve Kraemer, 2015). Geçmiş çalışmalarda cinsiyete yönelik olarak farklı sonuçların bulunması mevcut çalışmada cinsiyetin üç-boyutlu çok-kullanıcılı sanal ortamlarda buradalık üzerindeki etkisinin incelenmesini önemli k1lmaktadır.

\subsection{Araştırma Problemi}

Çok-kullanıcılı sanal bir ortamdaki katılımcıların buradalık düzeyleri ve buradalığa yönelik görüşleri nelerdir?

\subsubsection{Alt problemler}

1. Çok-kullanıcılı sanal ortamdaki katılımcıların buradalığı ne düzeydedir?

2. Çok-kullanıcılı sanal ortamdaki katılımcıların buradalık düzeylerinde cinsiyete göre bir farklılık var midır?

3. Çok-kullanıcılı sanal ortamdaki katılımcıların buradalığa yönelik görüşleri nelerdir?

\section{YÖNTEM}

\subsection{Araştırma Modeli}

Araştırmada betimsel tarama modeli kullanılarak üç-boyutlu çok-kullanıcılı sanal ortamdaki katılımcıların buradalık düzeyleri incelenmiş ve bu ortam hakkındaki görüşleri analiz edilmiştir. Araştırma, hem nicel hem nitel verilerin kullanılmış olması sebebiyle karma yöntem kullanılan bir araştırma olarak tanımlanabilir.

\subsection{Katılımcılar}

Çalışmanın katılımcılarını 2010-2011 eğitim-öğretim yılında İç Anadolu Bölgesindeki büyük bir devlet üniversitesinde, Eğitim Fakültesi Bilgisayar ve Öğretim Teknolojileri Eğitimi (BÖTE) bölümünde okuyan, Programlama Dilleri II dersinin bir şubesine devam etmekte olan 28 öğrenci oluşturmaktadır. Uygulamaya düzenli olarak katılmayan 4 kişinin verileri çıkarılmış, araştırma 24 kişi ile yürütülmüşsür. 


\subsection{Uygulama Süreci}

Uygulama sürecinde üç-boyutlu çok-kullanıcılı sanal ortam olarak Active Worlds platformu kullanılmıştır. Kişi sayısı 5 veya 6 olan toplam 5 grup oluşturulmuştur. Gruplar ilk yazar olan ders öğretim elemanı tarafından grup üyelerinin yeterlik ve bireysel özellikleri dikkate alınarak oluşturulmuştur. Öğrenciler ilk 8 hafta boyunca ders ile ilgili kuramsal konuları işlemiş ve bu süreçte proje önerilerini sunmuşlardır. Dönemin 9. haftasından itibaren öğrenciler geliştirecekleri proje konuları doğrultusunda kendi aralarındaki görüşmelerini hem laboratuvar saatlerinde hem de uzaktan Active Worlds platformu üzerinden gerçekleştirmişlerdir. Öğrencilere Active Worlds yazılımı sağlanmış, kullanıcı adları ile şifreleri gönderilmiştir. Araştırmacılar, katılımcıların üç-boyutlu çok-kullanıcılı sanal ortamda gerçekleştirdikleri proje görüşmelerine takım koçu olarak katılmıştır. Uygulamadan önce gruplar ve takım koçlarının arasındaki görev tanımları yapılmış ve takım koçlarının toplantı içeriğine olabildiğince karışmaması, yalnızca tartışma ortamını yönlendirmesi konusunda karar verilmiş ve bu durum öğrencilerle paylaşılmıştır. Takım koçları grupların projelerine yönelik müdahalelerde bulunmadan grup üyelerinin ortam üzerinden iletişim kurmalarına yardımcı olmuştur. Takım koçlarının görevi grup toplantılarına katılmak ve grup üyelerinin ortam hakkındaki tecrübe ve görüşlerine yönelik alan notlarını tutmak olarak belirlenmiştir.

Görev tanımları yapıldıktan sonra 4 haftalık süreçte her hafta her grubun en az bir kez sanal ortamda takım koçları ile birlikte sesli iletişim (VoIP) kurabilmeleri için toplantılar düzenlenmiştir. İlk hafta tüm gruplar ile deneme toplantısı gerçekleştirilmiş, ortamdaki sorunlar tespit edilerek her grubun görüşmelerini farklı saat aralıklarında gerçekleştirmeleri sağlanmıştır. $\mathrm{Bu}$ bağlamda her gruba özgü görüşme odaları düzenlenmiştir. Odaların dışına odanın ait olduğu grubun isminin yazılı olduğu panolar, odaların içine ise grup üyelerinin resim ve bilgilerinin olduğu bağlantılar yerleştirilmiştir. Ayrıca toplantı odalarına takım koçlarının da resim ve web sayfası bağlantıları eklenmiştir (Şekil 1).

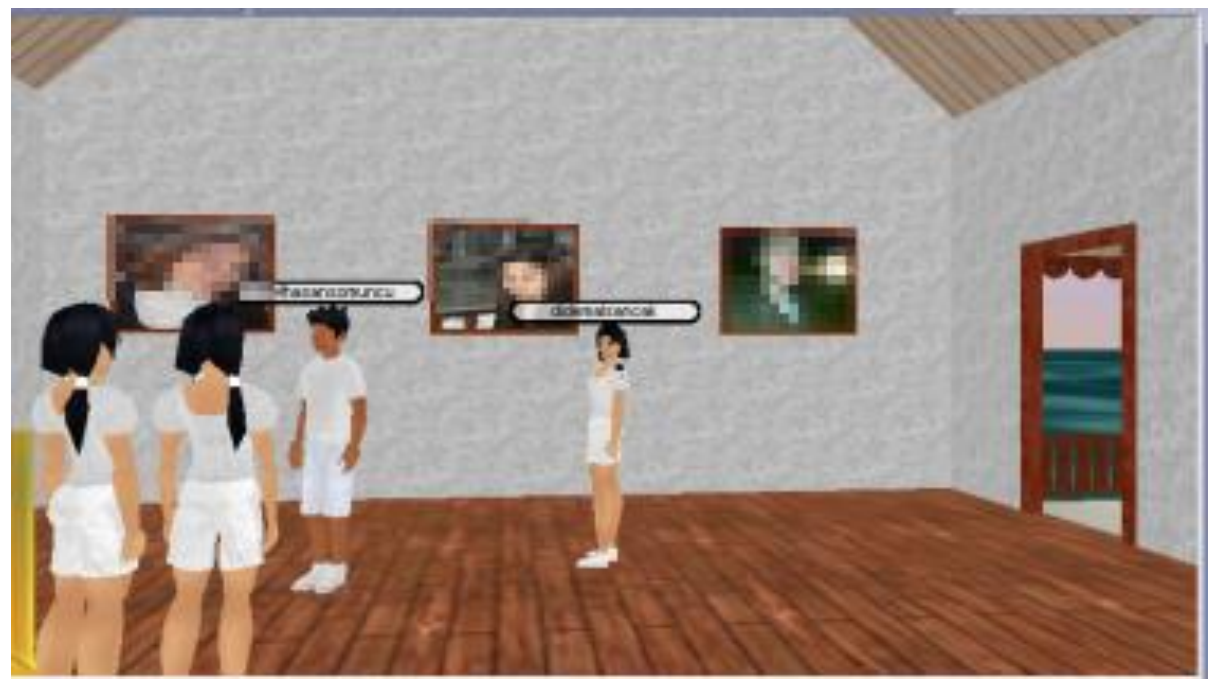

\section{Şekil 1. Active Worlds ortamındaki grup görüsşmelerine ait ekran görüntüsü}

Sanal ortamdaki grup toplantıları sesli ve görüntülü olarak kaydedilmiş, dönem sonunda katılımcılara Sosyal Buradalık Ölçeği ve Sanal Ortamda Buradalık Ölçeği uygulanmıştır. Ayrıca her gruptan bir öğrenci ile yarı-yapılandırılmış bir görüşme yapılmıştır. Görüşme yapılacak öğrencilerin seçiminde ortamdaki grup toplantılarına ilgisi ve katılımı yüksek olanlar tercih edilmiştir. Takım koçları AW ortamındaki görüşmelerden edindikleri izlenimleri alan notu olarak kaydetmişlerdir. 


\subsection{Veri Toplama Araçları}

Veri toplama aracı olarak Kişisel Bilgi Formu, Sosyal Buradalık Ölçeği ve Sanal Ortamda Buradalık Ölçeği kullanılmıştır. Ayrıca nitel verileri toplamak için yarı-yapılandırılmış görüşme formları ve alan notları kullanılmıştır.

Kişisel Bilgi Formu: Kişisel Bilgi Formu ile katılımcılara İnternet kullanım süreleri, bilgisayar kullanım süreleri, İnternet kullanma becerileri ve İnternete ulaşılan yer gibi bilgiler sorulmuştur.

Sosyal Buradalık Ölçeği: Kang, Choi ve Park (2007) tarafından geliştirilen, Olpak ve Çakmak (2010) tarafından Türkçe'ye uyarlanan, 5'li Likert türünde 19 maddeden oluşan Sosyal Buradalık Ölçeği çalışmada kullanılmıştır. Sosyal Buradalık Ölçeği ortak bulunuşluluk (5 madde), etkileme ( 7 madde) ve kaynaştırma (7 madde) olmak üzere üç alt faktörden oluşmaktadır. Sosyal Buradalık Ölçeği'nin Cronbach alfa değeri 0,94'tür. Alt faktörler için Cronbach alfa değerleri ise ortak bulunuşluluk için 0,79 , etkileme için 0,86 ve kaynaştırma için 0,91 'dir. Sosyal buradalık ölçeğinin bu çalışmada hesaplanan Cronbach alfa değeri ise 0,86 'dır. Alt faktörlerde ise ortak bulunuşluluk için 0,76 , etkileme için 0,78 ve kaynaştırma için 0,70 olarak hesaplanmıştır.

Sanal Ortamda Buradalık Ölçeği: Witmer ve Singer'ın (1998) geliştirip Özdinç'in (2010) Türkçe'ye uyarladığı Sanal Ortamda Buradalık Ölçeği çalışmada kullanılmıştır. Ölçek 7'li Likert türünde 30 maddeden oluşmaktadır. Sanal Ortamda Buradalık Ölçeği'nin Özdinç (2010) tarafından hesaplanan Cronbach alfa değeri 0,77'dir. Bu çalışmada hesaplanan Cronbach alfa değeri ise 0,83 'dür.

Yarı-Yapılandırılmış Görüşme Formu: Katılımcıların üç-boyutlu çok-kullanıcılı sanal ortam ile ilgili görüşlerinin belirlenmesi için araştırmacılar tarafından geliştirilen YarıYapılandırılmış Görüşme Formu kullanılmıştır. Görüşme formunda ortamın özellikleri, verimliliği, yüz-yüze görüşmelere göre avantaj ve dezavantajları ve ortam ile ilgili katılımc1 önerilerini içeren sorulara yer verilmiştir.

Alan Notları: Araştırmacılar, katılımcıların üç-boyutlu çok-kullanıcılı sanal ortamda gerçekleştirdikleri proje görüşmelerine takım koçu olarak katılmışlardır. Bu görüşmelerde gözlemci olarak yer almış ve sürece yönelik alan notları tutmuşlardır. Ayrıca sanal grup toplantıları araştırmacılar tarafından Camtasia Studio programı ile görüntülü ve sesli olarak kaydedilmiştir.

\subsection{Verilerin Analizi}

Nicel verilerin analizinde frekans, yüzde, ortalama ve Mann-Whitney $U$ analizi yapılmıştır. Takım koçları tarafından tutulan alan notları ve grup üyeleri ile yapılan görüşme verilerinin analizinde içerik analizi yapılmıştır. Verilerin analizi takım koçlarından ikisi tarafindan ayrı ayrı yapılmış, yapılan kodlamayla temalar ortaya çıkarılmıştır.

\section{BULGULAR}

\section{1. Ön Analizler}

Katılımcıların demografik özelliklerine göre (günlük İnternet kullanım süresi, İnternete bağlanılan yer, kaç yıldır İnternet kullandığı) dağılımlarını belirlemek için frekans ve yüzde hesaplaması yapılmıştır. Betimsel istatistik sonuçlarına göre, günlük İnternet kullanım süresinin 1-4 saat arası ve 4-8 saat arası seçeneğinde yoğunlaştığı, çoğunluğun İnternete evden ulaştığı, İnternet kullanım sürelerinin $3-5$ yıl arası ve 5 yıldan fazla seçeneğinde yoğunlaştığı görülmektedir. 


\subsection{Buradalık Düzeylerine İlişskin Bulgular}

Araştırmanın birinci alt problemi kapsamında katılımcıların çok-kullanıcılı sanal ortamdaki buradalık düzeylerini belirlemek için betimsel istatistiksel analiz yapılmıştır. Buradalık; sosyal buradalık ve sanal ortamda buradalık olarak ele alınmıştır. Analiz sonuçları Tablo 1 ve Tablo 2'de sunulmuştur.

Tablo 1. Sosyal buradalık ve alt faktörlerine ilişkin betimsel istatistik sonuçları

\begin{tabular}{lccccc}
\hline & $\mathbf{N}$ & $\bar{X}$ & Min & Max & SD \\
\hline Ortak bulunuşluluk & 24 & 17,6 & 13 & 24 & 3,3 \\
\hline Etkileme & 24 & 26 & 15 & 34 & 4,4 \\
\hline Kaynaştırma & 24 & 26,3 & 19 & 35 & 3,8 \\
\hline Toplam (Sosyal Buradalık) & 24 & 69 & 53 & 93 & 9,64 \\
\hline
\end{tabular}

Tablo 1 incelendiğinde sosyal buradalık ölçeğinden alınan toplam puanların ortalamasının 69 olduğu görülmektedir. Ölçeğin alt boyutlarından alınan puanların ortalaması ise, ortak bulunuşluluk için 17,6, etkileme için 26 ve kaynaştırma için 26,3'dür. Sosyal buradalık puanının 0 ile 95 arasında olabileceği göz önüne alındığında katılımcıların sosyal buradalık algılarının orta düzeyin üzerinde olduğu söylenebilir.

Tablo 2. Sanal ortamda buradalığa ilişkin betimsel istatistik sonuçları

\begin{tabular}{lccccc}
\hline & N & $\bar{X}$ & Min & Max & SD \\
\hline Sanal ortamda buradalık & 24 & 126 & 97 & 155 & 15,5 \\
\hline
\end{tabular}

Tablo 2 incelendiğinde Sanal Ortamda Buradalık Ölçeği'nden alınan puanların ortalamasının 126 olduğu görülmektedir. Sanal ortamda buradalık puanının 0 ile 210 arasında olabileceği göz önüne alındığında katılımcıların sanal ortamda buradalık algılarının da orta düzeyin üzerinde olduğu söylenebilir.

\subsection{Cinsiyet ve Buradalığa İlişsin Bulgular}

Araştırmanın ikinci alt problemi kapsamında katılımcıların buradalık düzeylerinin cinsiyete göre farklılaşıp farklılaşmadığını belirlemek için Mann-Whitney U testi yapılmıştır. Buradalık; sosyal buradalık ve sanal ortamda buradalık açısından ilgili ölçekler ile ölçülmüsstür. Analiz sonuçları Tablo 3 ve Tablo 4'de sunulmuştur.

Tablo 3. Katılımcıların sosyal buradalık puanlarının cinsiyete göre Mann-Whitney U testi sonuçları

\begin{tabular}{lccccc}
\hline Cinsiyet & N & $\begin{array}{c}\text { Sira } \\
\text { Ortalaması }\end{array}$ & $\begin{array}{c}\text { Sira } \\
\text { toplamı }\end{array}$ & U & p \\
Erkek & 11 & 12,05 & 132,5 & & \\
Kadın & 13 & 12,88 & 167,5 & 66,5 &, 771 \\
\hline
\end{tabular}

Tablo 3'deki Mann-Whitney U testi analiz sonuçları incelendiğinde çok-kullanıcılı sanal ortamda katılımcıların sosyal buradalık düzeylerinde erkekler ve kadınlar arasında istatistiksel olarak anlamlı bir farklılık bulunmamıştır $(\mathrm{u}=66,5 \mathrm{p}>, 05)$.

Tablo 4. Katılımcıların sanal ortamda buradalık puanlarının cinsiyete göre Mann-Whitney U testi sonuçları

\begin{tabular}{lccccc}
\hline Cinsiyet & $\mathbf{N}$ & $\begin{array}{c}\text { Sira } \\
\text { Ortalaması }\end{array}$ & $\begin{array}{c}\text { Sira } \\
\text { toplamı }\end{array}$ & $\mathbf{U}$ & $\mathbf{p}$ \\
Erkek & 11 & 13,59 & 150,5 & 59,5 &, 486 \\
Kadın & 13 & 11,58 & 149,5 & & \\
\hline
\end{tabular}


Tablo 4'deki Mann-Whitney U testi analiz sonuçları incelendiğinde çok-kullanıcılı sanal ortamda katılımcıların sanal ortamda buradalık düzeylerinde erkekler ve kadınlar arasında istatistiksel olarak anlamlı bir farklılık bulunmamıştır $(\mathrm{u}=59,5 \mathrm{p}>, 05)$.

\subsection{Ortam ve Buradalığa İlişkin Nitel Bulgular}

$\mathrm{Bu}$ bölümde nitel verilere dayanarak üç-boyutlu çok-kullanıcılı sanal ortamın buradalık açısından avantaj ve dezavantajları, görüşmelerde var olan buradalık göstergeleri, buradalık hissi oluşturan avatarların özellikleri ve buradalığa yönelik önerilere yer verilmiştir. Ayrıca ortamda yaşanan iletişim sorunlarının nedenleri ve katılımcıların ortam tercihleri sunulmuştur.

\subsection{1. Üç-boyutlu ortamın buradalık açısından avantaj ve dezavantajları}

Katılımcılar AW'nin buradalık üzerinde etkili olan avantajlarını ve dezavantajlarını Tablo 5'deki gibi ifade etmişlerdir.

Tablo 5. Katılımcı görüşleri doğrultusunda AW'nin avantajları ve dezavantajları

\begin{tabular}{ll}
\hline \multicolumn{1}{c}{ Avantajları } & \multicolumn{1}{c}{ Dezavantajları } \\
\hline Esnek erişim kolaylığı & $\begin{array}{l}\text { Toplantı yaparken ortama giren diğer kişilerin } \\
\text { seslerinin ortamdaki kişilerin sesleriyle karışması }\end{array}$ \\
\hline Görüşme yapabilme & Dosya gönderimi yapamama \\
\hline Etkileşim & Ortamdan düşmeler olması \\
\hline Çekingenliğin azalması & Çoklu katılımlarda yavaşlama \\
\hline Fikir paylaşımı/görüşlerini rahat belirtme & Ses iletimindeki kopukluklar \\
\hline Paylaşım, işbirliği, rekabete katkı sağlama & Ortak bir ekranı görememe \\
\hline Herkesin karakterinin olması & Ses ayarının düşük olması \\
\hline Avatar özelliklerini değiştirme & Programın hata vermesi \\
\hline Sesli iletişim sağlama & \\
\hline
\end{tabular}

Katılımcılar ses, dosya paylaşımı ve teknik sorunlar gibi dezavantajların orada olma (buradalık) hissi üzerinde olumsuz etkiye sahip olduğunu ifade ederken, etkileşim, işbirliği yapma ve çekingenliği azaltma gibi faktörlerin orada olma hissi üzerinde olumlu etkiye sahip olduğunu ifade etmişlerdir.

Katılımcı 5, üç-boyutlu ortamın bir avantajı olarak belirtilen görüşlerini daha rahat belirtme özelliğini "ilk önce ǚ̧-boyutlu ortamda sanki daha rahat düşüncelerimi dile getirdim. Yüz yüze olmayınca düşüncelerimi daha rahat dile getirebiliyorum." ifadesiyle desteklemiştir. Katılımc1 1 ise esnek erişim kolaylığı ve hakimiyet eşitliği gibi avantajları, "Benim kendi kafamda kurduğum hani kendi ortamlar kendi masaları kendi evleri orda daha rahat bir şekilde kendilerini hissedebiliyorlar. Diğer türlü bir ortamda kişi şey yapıyor biraz hani duruşu ile hareketi filan ortama hakim oluyor bazen, $o$ üç-boyutlu ortamda herkesde eşit bir görüntü var." ş̧eklinde ifade etmiştir. Katılımc1 2 "Bana çekici gelen yönleri kapalı ortamların filan olması, bir de yani üç-boyutlu olarak ortamların olması idi, bir de herkesin ayrı karakterinin olması tabi karaktere kendin şekil vermen filan artısiydl." diyerek yukarıdaki özelliklerden birkaçını içine alan görüşünü dile getirmiştir.

\subsubsection{Buradalık göstergeleri}

Ortamın katılımcılarda buradalık hissi uyandıracak özelliklerinin olmasından dolayı katılımcıların kullandıkları ifadelerin gerçek yaşamdakiyle aynı olduğu ve gerçekleştirdikleri eylemlerin gerçek yaşama uygun olmasını aradıkları dikkat çekmektedir. AW ortamında yapılan toplantılar esnasında katılımcıların ortamda sosyal olarak orada oldukları hissini yaşadıklarına dair bulgular elde edilmiştir. Katılımcıların ortama girdiğinde birbirlerini selamlamaları, kafalarına takılan konuları grup arkadaşlarına sormaları, yaptıkları projeye ilişkin buldukları bağlantıları paylaşmaları, yapılan işlere birlikte karar vermeleri, grup üyelerinden biri herhangi bir konuda mesaj gönderdiğinde buna karşıllk vermeleri, toplantı sonlandığında ortamdan ayrılırken veda etmeleri ve diğer üyelerden buna karşılık almaları buradalığa ait elde edilen bulgulardır. 


\subsubsection{Avatar kullanımı}

Katılımcıların çoğunluğu avatar kullanımıyla ilgili olarak ortamda kendilerini temsil eden avatarların olmasının, o ortamda olma (buradalık) hissi sağladığını ve oyun oynuyor hissi uyandırdığını belirtmiştir. Katılımcıların avatarlarla ilgili görüşleri ortamı görme tercihleri, avatarı kişiselleştirme nedenleri ve kişiselleştirmeme nedenleri şeklinde 3 başlıkta incelenmiştir.

Ortamı görme tercihi: Katılımcılardan dördü ortamı görme tercihi olarak avatarını arkadan görmeyi (üçüncü-kişi görüş açısı) seçerken biri ortamı avatarının gözünden görmeyi tercih etmiştir. Bunu seçme nedenleri olarak günlük yaşamda tepeden bakamama, bu şekilde daha rahat hareket etme, kendilerini temsil eden avatarı izleyebilme ve oyun ortamlarından aşina olmayı göstermişlerdir. Ancak avatarı tepeden görme tercihinde kapalı alanlara girilmek istendiğinde alanın dışında kalındığını belirtmişlerdir. Katılımeı 3 ortamda daha rahat hareket etme ifadesini "En çok uzaktan görmeyi kullandım. Çünkü öyle daha etkili yürüyordu. Daha rahat hareket edebildim." diyerek açıklamıştır. Ayrıca Katılıme1 1 "Ben genelde oyunlarda falan da kullandiğım karakteri görmek isterim. Bunda da aynı şekilde kendi karakterimi tepeden gördüm." şeklindeki görüşüyle oyun ortamlarına benzeterek bu ortamda da tepeden görmeyi tercih ettiğini söylemiştir. Ortamı görme tercihi olarak avatarın gözünden bakmak tercih edildiğinde ise katılımcıların bu konudaki görüşlerinde sosyal buradalık ve gerçeklik hissine vardıkları, gerçek yaşamla benzerlik kurdukları, etkileşim sağlıyormuş ve gerçekten yüz yüze konuşuyormuş hissini yaşadıkları görülmektedir. Katılımcı 2 bu konuda şu ifadeyi kullanmıştır: "Aslında kendi gözünle olduğu zaman daha iyi. Ortamda sanki daha bir etkileşim var. Şu an sanki yüz yüze konuşuyormuş gibi bir şey var. Ne bileyim daha bir gerçekçi duruyor. Kendim gerçekten de ben ordaymışım gibi. Ortamda abartılacak yer yoktu. Fantastik yerler yoktu. Günlük yaşamda gördüğ̈̈müz gibi bir alan, bir ortam vardl. Onun için gerçek yaşantıyla iç içeydi."

Avatarı kişiselleştirme nedeni: Katılımcılar avatarı kişiselleştirme nedenlerini ortamla bütünleşme, kendini yansıtma (kişisel özelliğini gösterme), kullanılabilirlik, farklı olma düşüncesi, olanağı değerlendirme (ilk ekranda karşılaşınca hemen değiştirme), oyun tecrübesine sahip olma ve herkesten farklı olma olarak açıklamıştır. Katılımcı 2 olanağ 1 değerlendirme ve farklı olma düşüncesini, "Herkes aynı görüntü[de] olmak istemiyor. Aynı görüntüde olmak ve farklı giysiler giymek çok farkl, bir şey yaptım sonuçta kendi etkileşim içinde olduğum ortamda. Sanki gerçek bir dünya üzerinde öyle beyaz tişört neden herkes gibi aynı şeyi giyeyim ki? İlk başta zaten doğduğum yerde bir yer çıtkt, ordan elbiseleri değiştirdim. Gayet de iyi oldu benim için." ifadesiyle desteklemektedir.

Avatarı kişiselleştirmeme nedeni: Avatarı kişiselleştirmeme nedeni olarak ortamı yalnızca görüşme için kullanma, tanıdığı insanlarla bir araya geldiği için kendisini göstermeye gereksinim duymama, isminin görünmesinin yeterli olduğunu düşünme, avatarı kişiselleştirmek için hangi arayüzü kullanacağını bilememe, avatarı kişiselleştireceği ekranın dikkat çekmemesi, gruptan kimse değiştirmediği için durumun farkında olmama, sınırlı zamana sahip olunduğundan dolayı ortamdaki bu özelliği keşfedememe ve İnterneti olmadığı için ortama katılamama/programı inceleyememe bulgularına ulaşılmıştır.

\subsubsection{Buradalık oluşmasına yönelik öneriler}

Katılımcılar üç-boyutlu ortamda buradalığın oluşmasına katkı sağlaması açısından ortamda dosya paylaşımı yapabilme, böylece dosya paylaşımını gerçekleştirirken de sürekli görüşme halinde kalabilme, aynı anda farklı gruplarla etkileşim içerisinde olma, üç-boyutlu ortamı daha gerçekçi hissetmek için ortamın sessiz olması, sesli iletişim sorununun düzeltilmesi, görüntülü konuşma özelliği ekleme, hataların giderilmesi ve avatarı değiştirme özelliğinin çaba göstermeden göze çarpması gibi öneriler dile getirmişlerdir. 


\subsubsection{Ortam tercihi}

Katılımcılardan kullandıkları ortamları karşılaştırmaları istendiğinde görüşme yapılan beş katılımcıdan üçünün yüz yüze ortamı tercih ettiği bulunmuştur. Katılımcılar tercih nedenlerini ise yüz yüze ortamda yapılan işlerde ciddiyet olması, üç-boyutlu ortamda işlerin baştan savma yapılması, yüz yüze ortamda işlerin daha hızlı ilerlemesi, üç-boyutlu ortamda işlem yapmanın sıkıntılı olması ve üç-boyutlu ortamda ortaya çıkan sorunların yapılan işleri aksatması olarak göstermektedir. Katılımc1 4 bu durumu "Sonuçta yüz yüze olduğu zaman daha bir ciddiyet oluyor o ortamda. Bilgisayar başıında bağlandı̆̆ımız zaman belki hedeflerimize ulaşabiliyoruz ama ne bileyim sanki biraz daha baştan savma oluyor gibi." görüşüyle özetlemiştir. Katılımc1 3 bu konuda "üçboyutluda işlem yapmak slkintıl oluyordu. Oradan dosya paylaş, sonra al onu düzenle, bir de ortak bir ekranı göremeyince sıkıntılar oluyordu. Yalnızca dosya aktararak yaptıklarımızı görebiliyoruz." görüșüne sahipken Katılımcı 5 ise bu durumu "üç-boyutlu ortamda bazı sıkıntılar meydana geliyor. Bu slkintılar büyük ihtimalle bizim sahip olduğumuz donanımlardan kaynaklanmakta. Bazen seste sorun oluyor ve yazmak zorunda kallyoruz. O yüzden yüz yüzenin daha avantajlı olduğunu düşünüyorum." görüşüyle desteklemektedir.

\subsubsection{Etkili görüşmelerin gerçekleşmeme nedenleri}

AW ortamında gerçekleştirilen toplantılarda ortamla, donanımla ve sesle ilgili sorunlar yaşandığında görüşmelerin etkili olamadığı görülmüştür. Kişi sayısının fazla olmasından dolayı ortamdan düşmelerin gerçekleşmesi, teknik sorunların yaşanması ve bunlara çözüm bulunamaması, grup üyeleri arasında iletişim sorunları yaşanması, mikrofon, kulaklık gibi donanımlara sahip olmama, proje dışı konuların görüşülmesi, farklı derslerde yapılan projelerin yoğunluğundan dolayı görüşmeye katılamama, görüşmenin farklı gruplarla aynı zamanda gerçekleşmesinden dolayı karışıklık yaşanması, mikrofondan kaynaklanan sorunların meydana gelmesi, ses iletiminde sorunların yaşanması, İnternet bağlantısının olmaması, bilgisayarın sistem özellikleri ve hızının ortama girmeye izin vermemesi gibi nedenlerden dolay1 yapılan görüşmelerin etkili olmadığı düşünülmektedir. Katılımc1 4 "Bunun sebebi İnternet bağlantıları olabilir büyük ihtimalle. Bilgisayartn kendi özellikleri ve sistem özellikleri olabilir. Ben evde kendi bilgisayarımdan bağlandiğım için ve bilgisayarım hızl olduğundan zorluk çekmedim yani çok az zorluk çektim ortama bağlanmakta." diyerek düşüncelerini ifade etmiştir.

\section{TARTIŞMA ve SONUÇ}

Bu çalışmada öncelikle üç-boyutlu çok-kullanıcılı sanal ortamları kullanan katılımcıların bu ortamlara yönelik buradalık düzeylerinin incelenmesi amaçlanmıştır. Katılımcıların üçboyutlu çok-kullanıcılı sanal ortamda buradalıklarının orta düzeyin üzerinde olduğu bulunmuştur. Süreç incelendiğinde selamlaşma, sorunları paylaşma ve sorunların çözümü konusunda karar alma gibi davranışların ortamda var olan buradalığın göstergesi olduğu söylenebilir. Alanyazındaki çalışmalarda elde edilen üç-boyutlu çok-kullanıcılı sanal ortamlarda katılımcıların sosyal buradalık algılarının yüksek olduğu sonucu bu çalışmanın sonucu ile paralellik göstermektedir (Papachristos, Vrellis, Natsis ve Mikropoulos, 2014; Yilmaz, Topu, Goktas ve Coban, 2013). Çalışmanın sonucu Dickey'in (2005) çalışması ile benzerlik göstermekte olup ilgili çalışmada çok-kullanıcılı sanal ortamların işbirlikli öğrenme deneyimi, orada olma algısı, buradalık algısı ve topluluk algısı sağladığı ifade edilmiştir. Nitekim bu çalışmada da kullanıcıların üç-boyutlu çok-kullanıcılı sanal ortam içerisinde bulunduklarını hissettikleri sonucuna ulaşılmıştır. Richardson ve Swan (2003) tarafından yapılan çalışmada öğrencilerin sosyal buradalık algılarının yüksek çıkması çalışmanın sonuçlarını açıklar niteliktedir. Benzer şekilde Tüzün ve Özdinç (2016) tarafından üniversiteye yeni başlayan öğrencilerin oryantasyonu için üç-boyutlu çok-kullanıcılı sanal ortamların kullanılabilirliğini değerlendirmek amacıyla yapılan çalışmada da katılımcıların yüksek düzeyde buradalığa sahip oldukları bulunmuştur. Sallnas (2005) tarafından yapılan benzer bir çalışmada ise katılımcıların 
ifade ettikleri buradalık ve sosyal buradalığın sesli sohbet ortamında yüksek olduğu bulunmuştur.

Cinsiyet açısından incelendiğinde ise katılımcıların buradalık düzeylerinin cinsiyete göre farklı1ık göstermediği sonucuna ulaşılmıştır. Alanyazında benzer şekilde cinsiyetin sosyal buradalık üzerine etkisinin olmadığı sonucuna ulaşılan çalışmalar bulunmaktadır (Cho, Yim ve Paik, 2015; Reisoğlu, 2014). Felnhofer ve arkadaşları (2014) tarafından yapılan çalışmada ise erkeklerin kadınlara göre daha fazla mekânsal buradalık, katılım ve orada olma hissine sahip olduğu; ama sosyal buradalık açısından cinsiyetler arası fark olmadığı sonucuna ulaşılmıştır. Diğer taraftan sosyal buradalık düzeyinde cinsiyete göre farklılık olduğu sonucuna ulaşılan çalışmalar da mevcuttur (deNoyelles ve Kyeong-Ju Seo, 2012; Richardson ve Swan, 2003; Siriaraya ve Ang, 2012; Thayalan, Shanthi ve Paridia, 2012). Buradalık açısından incelendiğinde alanyazında farklı sonuçlara ulaşılan çalışmalar mevcuttur. Bu çalışmada cinsiyete göre fark çıkmaması çalışma grubunun özelliğinden kaynaklanıyor olabilir. Örneğin Yıldız ve Tüzün (2011) ergenlik öncesi çocukların dahil olduğu bir çalışmada uzamsal görselleştirme ve zihinsel döndürme performansları açısından cinsiyetler arasında bir fark bulmamıştır. Bu çalışma bağlamında dersin öğretim elemanının öğrencilere yönelik eşitlikçi tutumu da fark çıkmamasına neden olmuş olabilir.

Öğrencilerle yapılan görüşmeler ve takım koçlarının alan notlarında ise buradalık göstergelerine, buradalığı etkileyen ortam özelliklerine, avatar kullanımının buradalığa etkisine ve öğrencilerin ortam tercihlerine yönelik sonuçlar ve öneriler ortaya çıkmıştır. Katılımcıların buradalık hissini yaşadıklarının göstergesi olarak kullandıkları ifadelerin gerçek yaşamdaki ifadeler ile aynı olması gösterilebilir. Grup üyelerinin derse karşı sorumluluklarını yerine getirmek için ortama katılım göstermelerinin yanında grup odasına giderek iletişimi başlatma ve devam ettirme, ortama katılma sürecinde selamlaşma, soru sorma, cevap verme ve birlikte karar verme durumlarının yaşanması buradalık hissinin yaşandığına dair verilebilecek örneklerdir. Sanal dünyalar sürükleyici bir ortamda avatarlar aracılığıyla fiziksel ve sosyal buradalığı sağlamaktadır. Kişiler sanal dünyada yüksek fiziksel ve sosyal buradalığa sahip olduğunda öğrenme etkinlikleriyle ve başkalarıyla etkileşim kurmakla daha fazla meşgul olacaktır (Cho, Yim ve Paik, 2015). Benzer şekilde Reisoğlu (2014) tarafından yapılan çalışmada yazılı sohbet ortamının sohbet etme, arkadaşını ortam hakkında bilgilendirme, kendini tanıtma, soru sorma, soruları cevaplama, yardım isteme ve yardım etme gibi amaçlar doğrultusunda kullanılmasının sosyal buradalığı olumlu olarak etkilediği ifade edilmiştir.

Üç-boyutlu ortamın buradalık üzerinde olumlu etkisi olan özellikleri paylaşımlar yapma, ortamda hep birlikte konuşarak zamandan kazanma, çoklu iletişim sağlama, soru sorabilme ve anında cevap alma ve karar vermek için bir araya gelme şeklinde sıralanmaktadır. Ortamın bu özelliklerini sosyal buradalık kavramıyla açıklamak mümkündür. Sosyal buradalık öğrenenin memnuniyeti kadar öğrenme süreci ve çıktılarında önemli bir rol oynamaktadır (Cho, Yim ve Paik, 2015). Üç-boyutlu ortamın buradalık üzerinde olumsuz etkisi olan durumların sebepleri ise teknik ve donanımsal aksaklıkların yaşanması, ses iletiminde yaşanan sorunlar ve katılımcıların ortama karşı önyargılarının olması şeklinde ifade edilebilir. Alanyazında yer alan çalışmalarda da benzer şekilde ses iletimi ve sesli sohbetin sıkıntılı olduğu ve yönetiminin zor olduğu ifade edilmiştir (Esteves, Fonseca, Morgado ve Martins, 2011).

Üç-boyutlu ortamın kullanımına yönelik dikkat çeken bir özellik katılımcıların üç-boyutlu oyunları oynamaya aşina olmaları sebebiyle üç-boyutlu ortamları da rahat bir şekilde kullanabilmeleridir. Konstantinidis ve arkadaşlarının (2009) yaptıkları çalışmada da daha fazla deneyimi olan kullanıcıların bu platformları üç-boyutlu bilgisayar oyunları ile karşılaştırdıkları belirlenmiş, bu kullanıcıların ortamı öğrenmeleri ve kullanmalarının daha kolay olduğu ifade edilmiştir. Benzer şekilde Reisoğlu (2014) tarafından yapılan çalışmada sosyal buradalık 
düzeyinin üç-boyutlu bilgisayar oyunu deneyimi olan öğrencilerde daha yüksek olduğu sonucuna ulaşılmıştır.

Katılımcıların ortamı kullanırken dikkat ettikleri bir konu avatar ve özellikleri olmuştur. Dans etme ve uçma gibi özellikler avatarların kullanıcıların dikkatini çeken yönlerindendir. Herrington'un (2010) çalışmasında öğrenciler hesap açma sistemine girmekte zorlanmasalar da avatarlarının görünümü değiştirmeleri bir saat kadar sürmüştür. Bu çalışmada katılımcıların bu özelliği kullanmamasındaki en önemli nedenler ortamı keşfetme olanaklarının olmaması ve ortamda çok fazla vakit geçirmemeleri olarak ortaya çıkmıştır. Görüş açısı tercihlerinde ise kendilerini uzaktan gösteren kamera bakışı özelliği (üçüncü-kişi görüş açısı) tercih edilmektedir. Bunun nedenlerinden bir tanesi "günlük yaşamda tepeden bakma" olanağının olmaması olabilir. Uygulama sürecine bakıldığında etkili görüşme ve iletişim konusunda sorunlar yaşanmıştır. Bu sorunların sebepleri görüşme saatlerinin uygunsuzluğu, İnternet bağlantısının olmaması, donanımsal sorunların yaşanması ve aynı süreçte başka projeler geliştirmek zorunda olduklarından dolayı katılımcıların ortama girecek zamanlarının kısıtlı olması şeklinde sıralanmıştır. Benzer bir sonuca ulaşan Yilmaz, Topu, Goktas ve Coban (2013) öğrencilerin düzenli olarak katılmaları gereken dersleri olduğu için birbirleri ile iletişim kurma zamanlarının kısıtlı olmasını bir sinırlılık olarak ifade etmiştir.

Görüşme yapılan beş katılımcıdan dördü yüz yüze ortamı tercih ettiğini ifade etmiştir. Buna gerekçe olarak sistemin yavaş işlemesi, teknik sorunlar ve bağlantı sorunları ifade edilmiş, ortamda kullanılan sesli iletişim (VoIP) özelliğinde ortaya çıkan aksaklıkların katılımcıların sağlıklı iletişimini engellediği bulunmuştur. Herington da (2010) çok-kullanıcılı sanal ortama katılan kişiler sesli konuşurken bazılarının bunu duyamaması konusundaki sıkıntıyı benzer şekilde belirtmiştir. Bir diğer çalışmada da İnternet hızı ve ses altyapısının süreci olumsuz etkilediği ifade edilmiştir (Baydaş ve diğerleri, 2015). Yine Herington (2010) ile Konstantinidis ve arkadaşları (2009) tarafından yapılan çalışmalarda video kartına sahip olmama, yetersiz işlemci ve bellek, düşük hızlı İnternet bağlantısı gibi teknik sorunlar ifade edilmiştir.

\section{5. ÖNERILLER}

- $\quad$ Süreç öncesinde öğrencilerin İnternet bağlantıları ve bant genişlikleri incelenmelidir. Böylece süreçte sorun yaşama potansiyeli olan öğrencilerin İnternet bağlantısı sorunları önceden giderilebilir.

- Görüşmelerde yaşanan teknik sorunların giderilmesi için teknik destek uzmanlarının ortamda olması sağlanabilir. Ya da grup koçlarının teknik konularda daha fazla bilgi sahibi olması sağlanarak öğrencilere bu konuda destek hizmeti vermesi sağlanabilir.

- $\quad$ Öğrencilerin ortama ilişkin dosya paylaşamama sorununu gidermek adına bu tür ortamlar üzerinden proje yürütülmesini kolaylaştırmak için dropbox gibi ortak dosya paylaşımı olanaklarını kullanmaları sağlanabilir.

- $\quad$ Öğrenciler avatarı kişiselleştirme sürecinde ortamı tam olarak bilmedikleri için zorlandıklarını ifade etmişlerdir. Bu sorunu gidermek adına süreç öncesinde öğrencilere sistem özelliklerini ve ortam üzerinde yapılabilecek temel işlemleri anlatan kısa bir bilgilendirme ya da oryantasyon yapilabilir.

- $\quad \mathrm{Bu}$ çalışmada buradalık düzeyinde cinsiyete göre bir farklılık bulunmamıştır. Yapılacak çalışmalarda farklı eğitim düzeyleri ve farklı konular ile uygulamalar yapılarak buradalık düzeyi cinsiyet açısından tekrar incelenebilir.

- $\quad \mathrm{Bu}$ çalışmada BÖTE bölümünde öğrenim gören küçük bir kullanıcı grubu ile çalışılmıştır. Farklı alanlarda, daha geniş kullanıcı toplulukları ile, farklı üç-boyutlu sanal dünya platformları kullanılarak çalışmalar gerçekleştirilebilir. 
- $\quad$ Bu çalışmada ses iletimi konusunda yaşanan teknik sorunlar sürecin etkililiğini olumsuz olarak etkilemiştir. Gelecek çalışmalarda araştırmacılar bu problemleri süreç öncesinde gidermelidir.

\section{KAYNAKLAR}

Aragon, S.R. (2003). Creating social presence in online environments. New Directions for Adult and Continuing Education, 100, 57-68.

Baydas, O., Karakuş, T., Topu, F.B., Yilmaz, R., Ozturk, M.E., \& Goktas, Y. (2015). Retention and flow under guided and unguided learning experience in 3D virtual worlds. Computers in Human Behavior, 44, 96-102.

Bulu, S.T. (2012). Place presence, social presence, co-presence, and satisfaction in virtual worlds. Computers \& Education, 58, 154-161.

Bulu, S.T. ve İşler, V. (2011). Second life odtü kampüsü. Akademik Bilişim 2011 Konferansında sunulan bildiri, Malatya.

Cho, Y., Yim, S, \& Paik, S. (2015). Physical and social presence in 3D virtual role-play for pre-service teachers. Internet and Higher Education, 25, 70-77.

Dalgarno, B., \& Lee, J.W. (2010). What are the learning affordances of 3-D virtual environments? British Journal of Educational Technology, 41(1), 10-32.

deNoyelles, A., \& Kyeong-Ju Seo, K. (2012). Inspiring equal contribution and opportunity in a 3d multi-user virtual environment: Bringing together men gamers and women non-gamers in Second Life. Computers \& Education, $58,21-29$.

Derks, D., Fischer, A.H., \& Bos, A.E.R. (2008). The role of emotion in computer-mediated communication: A review. Computers in Human Behavior, 24, 766-785.

Dickey, M.D. (2005). Three-dimensional virtual worlds and distance learning: Two case studies of Active Worlds as a medium for distance education. British Journal of Educational Technology, 36, 439-451.

Edirisingha, P., Nie, M., Pluciennik, M., \& Young, R. (2009). Socialisation for learning at a distance in a 3-D multiuser virtual environment. British Journal of Educational Technology, 40(3), 458-479.

Erlandson, B.E., Nelson, B.C., \& Savenye, W.C. (2010). Collaboration modality, cognitive load, and science inquiry learning in virtual inquiry environments. Educational Technology Research \& Development, 58(6), 693-710.

Esteves, M., Fonseca, B., Morgado, L., \& Martins, P. (2011). Improving teaching and learning of computer programming through the use of the Second Life virtual world. British Journal of Educational Technology, 42(4), 624-637.

Felnhofer, A., Kothgassner, O.D., Hauk, N., Beutl, L., Hlavacs, H., \& Kryspin-Exner, I. (2014). Physical and social presence in collaborative virtual environments: Exploring age and gender differences with respect to empathy. Computers in Human Behavior, 31, 272-279.

González, M.A., Santos, B.S.N., Vargas, A.R., Martín-Gutiérrez, J., \& Orihuela, A.R. (2013). Virtual worlds: Opportunities and challenges in the 21st century. Procedia Computer Science, 25, 330-337.

Gunawardena, C.N. (1995). Social presence theory and implications for interaction collaborative learning in computer conferences. International Journal of Educational Telecommunications, 1(2/3), 147-166.

Gunawardena, C.N., \& Zittle, F.J. (1997). Social presence as a predictor of satisfaction within a computer-mediated conferencing environment. The American Journal of Distance Education, 11(3), 8-26.

Hammick, J.K., \& Lee, M.J. (2014). Do shy people feel less communication apprehension online? The effects of virtual reality on the relationship between personality characteristics and communication outcomes. Computers in Human Behavior, 33(2014), 302-310.

Herrington, D. (2010). Evaluation of learning efficiency and efficacy in a multi-user virtual environment. Journal of Digital Learning in Teacher Education, 27(2), 66-75.

Kang, M., Choi, H., \& Park, S. (2007). Construction and validation of a social presence scale for measuring online learners' involvement. In C. Montgomerie \& J. Seale (Eds.), Proceedings of World Conference on Educational Multimedia, Hypermedia and Telecommunications (pp. 1829-1833). Chesapeake, VA: AACE.

Kim, J., Kwon, Y., \& Cho, D. (2011). Investigating factors that influence social presence and learning outcomes in distance higher education. Computers \& Education, 57, 1512-1520. 
Konstantinidis, A., Tsiatsos, T., \& Pomportsis, A. (2009). Collaborative virtual learning environments: Design and evaluation. Multimedia Tools and Applications, 44(2), 279-304.

Kreijns, K. (2004). Sociable CSCL environments. Social affordances, sociability, and social presence. Unpublished doctoral dissertation, Open University of the Netherlands, The Netherlands.

Kreijns, K., Kirschner, P.A., Jochems, W., \& VanBuuren, H. (2007). Measuring perceived sociability of computersupported colloborative learning environments. Computers \& Education, 49(2), 176-192.

Lee, K.M. (2004). Presence, explicated. Communication Theory, 14, 27-50.

McCreery, M.P., Schrader, P.G, Krach, S.K., \& Boone, R. (2013). A sense of self: The role of presence in virtual environments. Computers in Human Behavior, 29, 1635-1640.

Mikropoulos, T.A., \& Natsis, A. (2011). Educational virtual environments: A ten-year review of empirical research (1999-2009). Computers \& Education, 56(3), 769-780.

Newberry, B. (2001). Raising student social presence in online classes. Paper presented at World Conference on the WWW and Internet, Orlando, FL.

Olpak, Y.Z. ve Çakmak, E.K. (2009). E-öğrenme ortamları için sosyal bulunuşluk ölçeğinin uyarlama çalışması. Yüzüncü Yıl Üniversitesi Eğitim Fakültesi Dergisi, 6(1), 142-160.

Özdinç, F. (2010). Üç-boyutlu çok-kullanıcılı sanal ortamların oryantasyon amaçlı kullanılması. Yayımlanmamış yüksek lisans tezi, Hacettepe Üniversitesi, Ankara.

Papachristos, N.M., Vrellis, I., Natsis, A., \& Mikropoulos, T. (2014). The role of environment design in an educational multi-user virtual environment. British Journal of Educational Technology, 45(4), 636-646.

Parsons, T.D., Larson, P., Kratz, K., Thiebaux, M., Bluestein, B., Buckwalter, J.G., \& Rizzo, A.A. (2004). Sex differences in mental rotation and spatial rotation in a virtual environment. Neuropsychologia, 42(4), 555-562.

Perera, I., Allison, C., Nicoll, J.R., \& Sturgeon, T. (2009). Towards successful 3D virtual learning: A case study on teaching human computer interaction. International Conference for Internet Technology and Secured Transactions, London (pp. 1-6).

Prasolova-Forland, E. (2008). Analyzing place metaphors in 3D educational collaborative virtual environments. Computers in Human Behavior, 24(2), 185-204.

Reisoğlu, İ. (2014). 3B sanal ögrenme ortamlarında ögretimsel, sosyal ve bilişsel buradalık. Yayımlanmamış doktora tezi, Atatürk Üniversitesi, Eğitim Bilimleri Enstütüsü, Erzurum.

Richardson, J.C., \& Swan, K. (2003). Examining social presence in online courses in relation to students' perceived learning and satisfaction. The Journal of Asynchronous Learning Networks, 7(1), 68-88.

Sallnas, E.L. (2005). Effects of communication mode on social presence, presence and performance in collaborative virtual environments. Journal of Presence: Teleoperators and Virtual Environments, 14(4), 434-449.

Short, J., Williams, E., \& Christie, B. (1976). The social psychology of telecommunications. London: John Wiley \& Sons.

Siriaraya, P., \& Ang, C.S. (2012). Characteristics and usage patterns of older people in a 3D online multi-user virtual environment. Computers in Human Behavior, 28, 1873-1882.

So, H.J., \& Brush, T.A. (2008). Student perceptions of collaborative learning, social presence and satisfaction in a blended learning environment: Relationships and critical factors. Computers \& Education, 51(1), 318-336.

Steuer, J. (1992). Defining virtual reality: Dimensions determining telepresence. Journal of Communication, 42(4), 73-93.

Thayalan, X., Shanthi, A., \& Paridia, T. (2012). Gender difference in social presence experienced in e-Learning activities. Procedia - Social and Behavioral Sciences 67,(2012), 580-589.

Tor, H. ve Erden, O. (2004). İlköğretim öğrencilerinin bilgi teknolojilerinden yararlanma düzeyleri üzerine bir araştırma. The Turkish Online Journal of Educational Technology, 3(1), 120-130.

Tu, C.H. (2000a). Strategies to increase interaction in online social learning environments. Paper presented at Society for Information Technology and Teacher Education International Conference, San Diego, California.

Tu, C.H. (2000b). On-line learning migration: From social learning theory to social presence theory in a CMC environment. Journal of Network and Computer Application, 23(1), 27-37. 
Tüzün, H. (2010). Dünya üzerine yayılmış çok-kullanıcılı çevrim-içi eğitsel bir bilgisayar oyununun teknik yapısı ve Türkiye'de yaklaşımlar. In G. Telli-Yamamoto, U. Demiray, \& M. Kesim (Eds.), Türkiye'de e-öğrenme: Gelişmeler ve uygulamalar (pp. 261-281). Ankara, Turkey: Cem Web Ofset.

Tüzün, H., \& Özdinç, F. (2016). The effects of 3D multi-user virtual environments on freshmen university students' conceptual and spatial learning and presence in departmental orientation. Computers \& Education, 94, 228-240.

Walter, J.B., \& Burgoon, J.K. (1992). Relational communication in computer-mediated interaction. Human Communication Research, 19(1), 50-88.

Whiteman, J.A.M. (2002). Interpersonal communication in computer mediated learning. (ERIC Document Reproduction Service No. ED465997)

Williams, K.D. (2014). The effects of dissociation, game controllers, and 3D versus 2D on presence and enjoyment. Computers in Human Behavior, 38, 142-150.

Witmer, B.G., \& Singer, M.J. (1998). Measuring presence in virtual environments: A presence questionnaire. Presence: Teleoperators and Virtual Environments, 7(3), 225-240.

Wua, J., Mattingly, E., \& Kraemer, P. (2015). Communication in virtual environments: The influence of spatial cues and gender on verbal behavior. Computers in Human Behavior, 52(2015), 59-64.

Yıldız, B., \& Tüzün, H. (2011). Üç-boyutlu sanal ortam ve somut materyal kullanımının uzamsal yeteneğe etkileri. Hacettepe Üniversitesi Eğitim Fakültesi Dergisi, 41, 498-508.

Yilmaz, R.M., Topu, F.B., Goktas, Y. \& Coban, M. (2013). Social presence and motivation in 3D virtual worlds: An explanatory study. Australasian Journal of Educational Technology, 29(6), 823-839.

\section{Extended Abstract}

The aim of the present study is to analyze the presence levels of students who use threedimensional multi-user virtual environments, which present new opportunities for higher education. The sample comprised 24 students who attended a section of the Programming Languages II course in a Computer Education and Instructional Technology Department at a large state university in Central Anatolia Region of Turkey in the 2011 Spring semester. Within the scope of the course, students were asked to prepare a term project in groups. In order to decrease the meeting problems, the course instructor presented the students with the Active Worlds as an additional environment so that the groups could hold online meetings. Five groups were formed and each had 5-6 participants. The groups were formed on the basis of group members' competencies and individual characteristics. Students learned about theoretical subject matter related to the course for 8 weeks and presented their suggestions in this process. From the 9th week on, students held meetings in the laboratory hours and in the Active Worlds platform within the scope of their project topics. The students were provided with the Active Worlds software, usernames and passwords. The researchers participated in the project meetings in the three-dimensional multi-user environment as team coaches. After their job definitions were made, every week within the four-week process, meetings were held so that each group could contact their team coach in the virtual environment at least once a week. In this process, students' group meetings in the virtual environment were audio and video recorded. At the end of the process, students' social awareness and presence levels were analyzed and their opinions regarding the virtual environment were obtained. As data collection instruments, Social Presence Scale developed by Kang, Choi, and Park (2007) and adapted to Turkish by Olpak and Çakmak (2010) and Virtual Environment Presence Questionnaire developed by Witmer and Singer (1998) and adapted to Turkish by Özdinç (2010) were used. Furthermore, in order to collect qualitative data, semistructured interview forms and field notes taken by group coaches were used.

At the end of the study, it was found that participants' level of social presence and presence in the three-dimensional multi-user virtual environment were above the medium level. An analysis of the process revealed that behaviors like greeting, sharing problems, and solution to problems are indicators of social presence. This result is in line with that of Dickey's (2005). Dickey (2005) had found that multi-user virtual environments provide a cooperative learning experience, perception of being there, perception of presence, and community. Results of Richardson and Swan (2003) and Sallnas (2005) are in line with that of the present study.

In addition, it was found that participants' social presence and presence in virtual environment levels did not differ in terms of gender. However, other studies have found gender differences regarding 
the social presence levels (Richardson \& Swan, 2003; Thayalan, Shanthi, \& Paridia, 2012). In this study, the lack of gender differences can be explained by the instructor's egalitarian attitudes towards the students.

In the interviews and field notes, information on the environment's efficiency and suitability for cooperative study was obtained and suggestions were presented. Four out of the five interviewed participants stated that they would prefer face-to-face environment. They explained that slow processing of the system, technical problems, and connection problems and problems in voice communication (VoIP) prevented healthy communication among the participants. Herington (2010) also stated that people who participate in multi-user virtual environments had difficulty getting their voice heard when speaking. Similarly, studies by Herington (2010) and Konstantinidis et al. (2009) reported technical problems like lack of video cards, insufficient processors and memory, and slow Internet connections.

Another striking finding related to the three-dimensional environment is that participants can easily use three-dimensional environments since they are used to playing three-dimensional games. In a study by Konstantinidis et al. (2009), students with more experience compared these platforms with threedimensional computer games and it was easier for these users to learn about this environment. In addition, the present study found that participation in the meetings was low in some situations. The underlying reasons were the inconvenient meeting hours, lack of Internet connection, and the necessity to develop other projects at the same time.

The reasons for preferring the three-dimensional environment were sharing entertaining posts, sparing time by talking with everybody, chance to meet in situations when it is difficult to meet face-toface (in the evenings), simultaneous multi-user communication advantage, chance to ask questions, and making decisions together. The reasons for not preferring the three-dimensional environment were technical and hardware related problems, finding the environment unnecessary, having limited time for joining the environment due to other projects, and prejudice against the environment.

Future studies might investigate precautions and solutions regarding the determined problems. For instance, in order to find instant solutions to the problems, technical support experts may be available or group coaches may be more knowledgeable about this issue and hence share their knowledge with students. Social presence and presence in virtual environments may be investigated with different samples or through different educational activities. 